\title{
Can heterotrophic uptake of dissolved organic carbon and zooplankton mitigate carbon budget deficits in annually bleached corals?
}

\author{
Stephen Levas ${ }^{1,4}{ }^{1} \cdot$ Andréa G. Grottoli $^{1} \cdot$ Verena Schoepf $^{1,5} \cdot$ Matthew Aschaffenburg $^{2}$ • \\ Justin Baumann $^{1,6} \cdot$ James E. Bauer $^{3} \cdot$ Mark E. Warner $^{2}$
}

Received: 1 July 2015/ Accepted: 8 December 2015

(C) Springer-Verlag Berlin Heidelberg 2015

\begin{abstract}
Annual coral bleaching events due to increasing sea surface temperatures are predicted to occur globally by the mid-century and as early as 2025 in the Caribbean, and severely impact coral reefs. We hypothesize that heterotrophic carbon (C) in the form of zooplankton and dissolved organic carbon (DOC) is a significant source of C to bleached corals. Thus, the ability to utilize multiple pools of fixed carbon and/or increase the amount of fixed carbon acquired from one or more pools of fixed carbon (defined here as heterotrophic plasticity) could underlie coral acclimatization and persistence under future ocean-
\end{abstract}

Communicated by Biology Editor Dr. Anastazia Banaszak

Electronic supplementary material The online version of this article (doi:10.1007/s00338-015-1390-z) contains supplementary material, which is available to authorized users.

Stephen Levas

stephen.levas@villanova.edu

1 School of Earth Sciences, The Ohio State University, Columbus, OH 43210, USA

2 School of Marine Sciences and Policy, University of Delaware, Lewes, DE 19716, USA

3 Aquatic Biogeochemistry Laboratory, Department of Evolution, Ecology, and Organismal Biology, The Ohio State University, Columbus, $\mathrm{OH} 43210$, USA

4 Present Address: Department of Geography and the Environment, Villanova University, Villanova, PA 19460 , USA

5 Present Address: ARC Centre of Excellence for Coral Reef Studies, School of Earth and Environment, and UWA Oceans Institute, The University of Western Australia, Crawley, WA 6009, Australia

6 Present Address: Department of Marine Sciences, University of North Carolina, Chapel Hill, NC 27599, USA warming scenarios. Here, three species of Caribbean coral-Porites divaricata, P. astreoides, and Orbicella faveolata-were experimentally bleached for 2.5 weeks in two successive years and allowed to recover in the field. Zooplankton feeding was assessed after single and repeat bleaching, while DOC fluxes and the contribution of DOC to the total $\mathrm{C}$ budget were determined after single bleaching, 11 months on the reef, and repeat bleaching. Zooplankton was a large $\mathrm{C}$ source for $P$. astreoides, but only following single bleaching. DOC was a source of $\mathrm{C}$ for single-bleached corals and accounted for $11-36 \%$ of daily metabolic demand $\left(\mathrm{CHAR}_{\mathrm{DOC}}\right)$, but represented a net loss of $\mathrm{C}$ in repeat-bleached corals. In repeat-bleached corals, DOC loss exacerbated the negative $\mathrm{C}$ budgets in all three species. Thus, the capacity for heterotrophic plasticity in corals is compromised under annual bleaching, and heterotrophic uptake of DOC and zooplankton does not mitigate $\mathrm{C}$ budget deficits in annually bleached corals. Overall, these findings suggest that some Caribbean corals may be more susceptible to repeat bleaching than to single bleaching due to a lack of heterotrophic plasticity, and coral persistence under increasing bleaching frequency may ultimately depend on other factors such as energy reserves and symbiont shuffling.

Keywords Coral $\cdot$ Zooplankton $\cdot$ DOC $\cdot$ Bleached . Annual · Heterotrophy

\section{Introduction}

Coral reefs are threatened globally due to mass bleaching events that are already causing coral reef decline worldwide (Wilkinson 2008). Bleaching events are expected to increase in frequency and intensity in the coming decades 
(Hoegh-Guldberg 1999; Donner et al. 2007; Frieler et al. 2013). At the current rate of greenhouse gas emissions and warming sea surface temperatures (SSTs), models predict that reefs globally will experience annual bleaching events by 2040, with parts of the Caribbean potentially experiencing annual bleaching events as soon as 2025 (van Hooidonk et al. 2015).

At sustained elevated SSTs, corals lose their endosymbiotic algae (Symbiodinium spp.) rendering them pale white or bleached (Jokiel and Coles 1990; Glynn 1996; Brown 1997; Hoegh-Guldberg 1999; D’Croz et al. 2001). While healthy scleractinian corals can obtain up to $100 \%$ of their daily metabolic demand from the translocated photosynthate of their endosymbiotic algae, dramatic decreases in photosynthesis in single-bleached and some repeatbleached corals can lead to coral carbon (C) budget deficits of up to $80 \%$ (Muscatine et al. 1981; Falkowski et al. 1993; Grottoli et al. 2006; Palardy et al. 2008; Tremblay et al. 2012; Grottoli et al. 2014). To recover from bleaching, corals may rely on a combination of alternative sources of fixed carbon such as energy reserves and/or increased heterotrophy in conjunction with recovery of photosynthesis.

In addition to autotrophically acquired $\mathrm{C}$, both healthy and stressed corals can obtain up to $150 \%$ of fixed carbon from the ingestion of zooplankton (Grottoli et al. 2006; Palardy et al. 2008; Anthony et al. 2009; Houlbreque and Ferrier-Pages 2009; Grottoli et al. 2014), pico- and nanoplankton (Tremblay et al. 2012), non-living sedimentary and particulate organic matter (Anthony 1999, 2000; FerrierPages et al. 2011; Leal et al. 2014), and dissolved organic matter (Tremblay et al. 2012). For example, singly bleached corals Montipora capitata and Porites astreoides increase their zooplankton consumption and can meet more than $100 \%$ of their metabolic demand (heterotrophically plastic), thus replenishing or maintaining energy reserves during bleaching events (Grottoli et al. 2006; Rodrigues and Grottoli 2007; Palardy et al. 2008; Grottoli et al. 2014). Even in corals that do not increase their heterotrophic organic $\mathrm{C}$ intake when bleached, such as $P$. lobata and $P$. compressa, heterotrophically acquired zooplankton $\mathrm{C}$ still represents a significant component (25 and $40 \%$, respectively) of their total fixed C budgets (Grottoli et al. 2006; Palardy et al. 2008). However, for the Caribbean corals $P$. divaricata and Orbicella faveolata, zooplankton heterotrophy represents $<4 \%$ of their total fixed $\mathrm{C}$ budgets, irrespective of bleaching status or bleaching frequency (Grottoli et al. 2014). Thus, zooplankton heterotrophy is highly species specific and varies based on single versus sequential annual bleaching. However, little is known about Caribbean coral preferences for zooplankton size and species. If bleached Caribbean corals selectively capture a specific group and/or size of zooplankton similar to Hawaiian corals (Palardy et al. 2008), changes in zooplankton communities could potentially have drastic effects on bleached coral recovery.

In recent years, dissolved organic carbon (DOC) has been increasingly recognized as another source of fixed carbon for corals and may play an important role in coral resistance to bleaching. Healthy corals are typically net producers of DOC (Haas et al. 2010; Naumann et al. 2010, 2012; Levas et al. 2015) via the release of mucus and/or dissolved organic materials that account for losses of 5-45\% of photosynthetically fixed C (Crossland et al. 1980; Edmunds and Davies 1986; Crossland 1987; Bythell 1988; Ferrier-Pages et al. 1998; Tanaka et al. 2009), although DOC can be utilized by some corals (Naumann et al. 2010; Tremblay et al. 2012). However, temperature stress and bleaching may at times influence coral net DOC fluxes. For example, Haas et al. (2010) observed greater DOC losses from temperature-stressed coral, while Niggl et al. (2009) and Levas et al. (2015) found no differences in DOC fluxes between temperature-stressed and control corals.

DOC uptake could help mitigate or offset the loss of autotrophic $\mathrm{C}$ during bleaching events in Caribbean corals, which could experience annual bleaching by 2025 (van Hooidonk et al. 2015). However, such heterotrophic plasticity could potentially be influenced by the frequency of bleaching events as seen with zooplankton heterotrophy in bleached $P$. astreoides (Grottoli et al. 2014). To test these hypotheses, we quantified the proportion of coral organic $\mathrm{C}$ budgets derived from DOC fluxes and compared it with those derived from symbiont photosynthesis and zooplankton feeding from Grottoli et al. (2014) in singly bleached, repeat-bleached, and non-bleached control fragments of three ecologically important species of Caribbean corals. Understanding and quantifying changes in the various components of carbon budgets for singly and repeatedly bleached corals are essential for determining potential coral resilience to predict future increases in SST.

\section{Materials and methods}

Coral collection, acclimation, experimental design, and procedures used in this study have been largely described previously by Grottoli et al. (2014). Briefly, fragments of Porites divaricata, P. astreoides, and Orbicella faveolata were collected from the reefs near Puerto Morelos, Mexico, from July 4 to 9, 2009 (Electronic Supplementary Material, ESM, Table S1). After 5-d acclimation (July 14, 2009), half of the fragments from each colony and species were placed into tanks where the temperature was slowly increased over $5 \mathrm{~d}$ (to $31.5 \pm 0.20{ }^{\circ} \mathrm{C}$ ) (single bleaching treatment) and the other half of the fragments were kept in ambient control tanks (30.66 $\left.\pm 0.24^{\circ} \mathrm{C}\right)$ (Fig. 1a). On July 
29, 2009, after $15 \mathrm{~d}$, the heaters in the treatment tanks were turned off, and one-third of the bleached and control fragments were collected and immediately frozen. The other fragments were transplanted back to the reef at $4.9 \mathrm{~m}$ depth $\left(20^{\circ} 52.815^{\prime} \mathrm{N}, 86^{\circ} 50.989^{\prime} \mathrm{W}\right)$. After 11 months on the reef (June 20, 2010), one treatment and control fragment from each colony of each species was collected and DOC fluxes were measured from June 20 to 26, 2010, according to methods described below (Fig. 1a).

On July 22, 2010, the bleaching experiment was repeated with the remaining treatment corals from the previous year exposed to elevated temperatures again $\left(31.6 \pm 0.24{ }^{\circ} \mathrm{C}\right)$ (repeat bleaching treatment), while the control fragments from 2009 were maintained at ambient temperature $\left(30.4 \pm 0.23^{\circ} \mathrm{C}\right)$. At the end of $17 \mathrm{~d}$ (7 August 2010), heaters were turned off. DOC fluxes were measured August 5-10, 2010, and all the fragments were placed back on the reef. Feeding rates were quantified a week later, on August 15 and 17, 2010 (see below), according to Palardy et al. (2008).

The feeding fragment samples from the single bleaching experiment done in 2009 were inadvertently discarded (Grottoli et al. 2014). Thus, in order to obtain DOC fluxes and feeding rates, and calculate a total carbon budget, a second single bleaching experiment was conducted from June 28, 2010, to July 15, 2010. Two new coral fragments from nine different parent colonies from the same location of $P$. divaricata, P. astreoides, and O. faveolata (Fig. 1b) were collected and are referred to as redo corals. Half of the corals were exposed to elevated temperatures $\left(31.24 \pm 0.21{ }^{\circ} \mathrm{C}\right)$, and the other fragments remained at ambient control temperatures $\left(29.47 \pm 0.22{ }^{\circ} \mathrm{C}\right)$. After 17 d (July 15, 2010), heaters were turned off and DOC fluxes were measured from July 13 to 18, 2010. All coral fragments were transplanted to the reef for 1 week, and then,

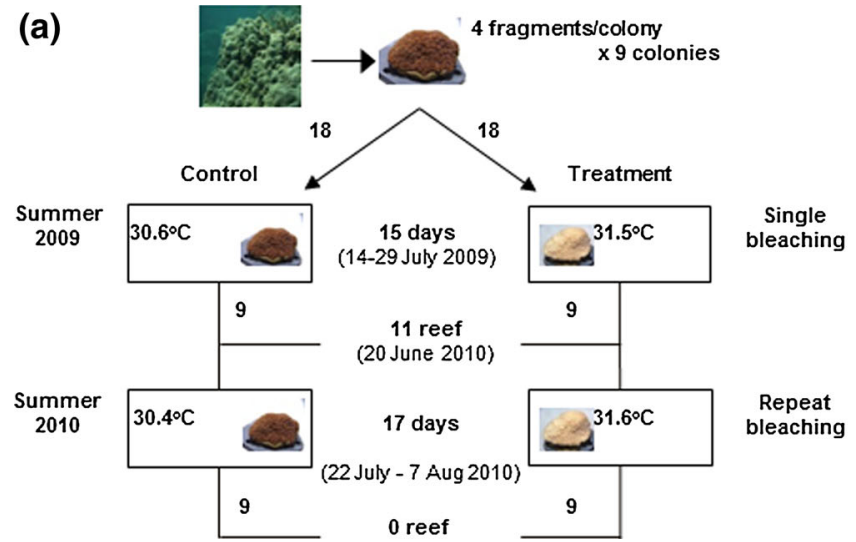

Fig. 1 Experimental design for a the single and repeat bleaching experiment of 2009-2010 for Porites divaricata, P. astreoides, and Orbicella faveolata and $\mathbf{b}$ the single bleaching experiment of 2010 for O. faveolata . Days $=$ number of days corals were in the tanks, feeding rates were determined in situ according to Palardy et al. (2008) (see below). Since these corals had not yet had the opportunity to recover except for 1 week on the reef, they are referred to as singly bleached corals. Differences between discarded samples and these corals should be minimal as these corals were collected from the same populations of corals as the initial single and repeat bleaching experiments and were subjected to similar temperature regimes. Thus, differences between single and repeat-bleached corals are most likely due to differences in experimental thermal history (Grottoli et al. 2014).

\section{Coral feeding measurements}

On July 27, 2010, four clear 50-L polypropylene plastic chambers with $50-\mu \mathrm{m}$ Nitex screen windows were placed over half of the redo corals for $12 \mathrm{~h}$ during the day. The Nitex screen windows allowed for sufficient flow but prevented zooplankton from entering the chambers (Palardy et al. 2005), enabling the corals to fully empty their guts. One hour after dusk, the chambers were removed and the coral fragments were allowed to feed on the natural assemblage of zooplankton and seston on the reef. After $1 \mathrm{~h}$ of feeding, the fragments were collected and fixed in formalin to prevent digestion of ingested zooplankton. On July 29, 2010, this procedure was repeated with the remainder of the single-bleached and control fragments. Within $48 \mathrm{~h}$, all or 150 polyps (whichever came first) of the coral fragments were dissected (Palardy et al. 2005) under a dissecting microscope (20 to $100 \times$ power) by probing with a dissection needle and subsequent scraping of the skeleton to expose any remaining zooplankton (Palardy et al. 2008). Prey larger than $50 \mu \mathrm{m}$ were visible, and only plankton inside the polyp were counted. The number of zooplankton eaten per polyp as well as the prey taxon and

(b)

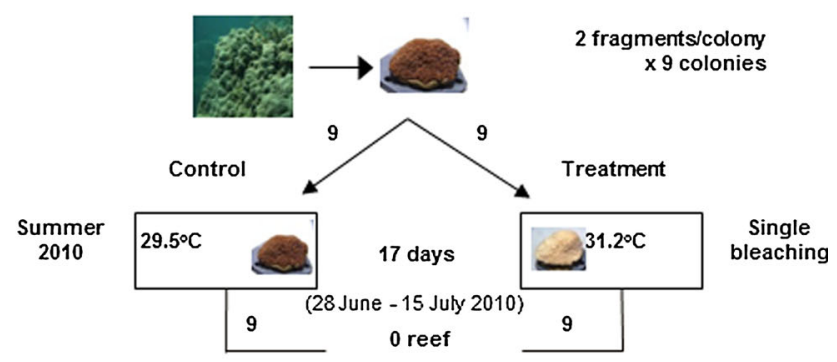

reef $=$ number of months corals were on the reef, feed $=$ coral fragments used for feeding measurements, and numbers indicate number of fragments collected. Diagram modified from Grottoli et al. (2014) 
size was recorded. Size was determined using a stage micrometer. If a consumed plankter could not be identified, it was classified as unidentified, but size was measured. Feeding rates were standardized to grams ash-free dry weight of each coral fragment (plankton captured $\mathrm{h}^{-1} \mathrm{~g}^{-1}$ dw). On August 13 and 17, 2010, the same procedure was repeated to measure feeding rates of repeat-bleached and control corals.

Each night, while the corals were feeding, at least two vertical plankton tows from $4 \mathrm{~m}$ depth to the surface were taken using a 0.5 -m-diameter plankton net with $50-\mu \mathrm{m}$ mesh. The tows were performed within $10 \mathrm{~m}$ of the experimental site and passed through a columnar sieve with $800-$, 400-, 150-, and 50- $\mu \mathrm{m}$ filters and preserved in $10 \%$ formalin. These size-fractioned samples were sorted and counted in broad taxonomic groups (ostracods, shrimp, eggs, isopods, snails, Cumacea, amphipods, polychaetes, crab zoea, and unidentifiable).

\section{DOC flux experiments}

DOC fluxes were measured outdoors using the respective treatment water (i.e., bleached corals received elevated temperature, while the controls received ambient water) under the same light used in the experiment in submerged closed-top UV-transparent acrylic chambers according to Levas et al. (2015). Briefly, two sets of incubations were conducted between 1000 and $1600 \mathrm{~h}$ and between 2000 and $0200 \mathrm{~h}$ over $6 \mathrm{~d}$ at each time point. One chamber contained no coral fragment and served as a control. It took $3 \mathrm{~d}$ to complete the incubations for the bleached fragments $(1 \mathrm{~d}$ per species) and an additional $3 \mathrm{~d}$ to complete the incubations for the non-bleached control fragments $(1 \mathrm{~d}$ per species).

Immediately after all chambers were sealed, two 1-L seawater samples were taken from the flow-through tank inflow, representing the background initial seawater DOC concentrations. After $1.5 \mathrm{~h}$ of incubation, each chamber lid and coral fragment were removed and the seawater from each chamber was collected into individual 1-L polycarbonate brown bottles pre-cleaned with $10 \%$ trace metalgrade $\mathrm{HCl}$ and placed on ice. One $30-\mathrm{mL}$ seawater aliquot was taken for DOC analysis from each brown bottle. Duplicate $30-\mathrm{mL}$ seawater aliquots were taken from the control chamber. A duplicate $30-\mathrm{mL}$ aliquot was randomly collected from one of the coral chambers. The procedure was identical for the second set of incubations.

Seawater samples were kept frozen at $-20{ }^{\circ} \mathrm{C}$ until analysis by high-temperature catalytic oxidation (HTCO) using a Shimadzu TOC 5050 in the Aquatic Biogeochemistry Laboratory at The Ohio State University according to Levas et al. (2015). The standard deviation of replicate measurements of a glucose standard was $\pm 4 \%$ $(n=100)$.

For each set of incubations, the average of the initial DOC concentrations was corrected for potential microheterotrophic and microautotrophic biases by subtracting the average of the control DOC concentrations from the same incubation set. The DOC flux for each fragment was calculated as the difference between the measured DOC concentration and the corrected initial DOC concentration for its incubation set and standardized to the fragment surface area as determined by the foil technique (Marsh 1970). Negative fluxes indicated a net uptake of DOC, whereas positive fluxes indicated a net release of DOC into the incubation chambers.

\section{Contribution of DOC to coral respiration}

The percent contribution of zooxanthellae (Symbiodinium spp.) to animal respiration (CZAR, Muscatine et al. 1981), contribution of zooplankton heterotrophy to animal respiration (CHAR $\mathrm{ZOO}_{\mathrm{ZOO}}$, Grottoli et al. 2006), and the total acquired fixed carbon (CTAR, sum of CZAR and CHAR $\mathrm{ZOO}_{\mathrm{ZO}}$ ) for the same fragments used in this study were calculated as in Grottoli et al. (2014). In this study, the percent contribution of DOC to heterotrophy was also calculated $\left(\mathrm{CHAR}_{\mathrm{DOC}}\right.$, Levas et al. 2015) relative to respiration and a new comprehensive total carbon budget (i.e., CTAR) was calculated as the sum of CZAR, $_{\text {CHAR }}$ ZOO, and CHAR ${ }_{\text {DOC }}$.

$\mathrm{CHAR}_{\mathrm{DOC}}$ for each fragment was calculated as the sum of daytime and nighttime DOC fluxes in $\mu \mathrm{g} \mathrm{C}$ standardized to grams ash-free dry weight $\mathrm{hr}^{-1}\left(D O C_{f}\right)$, divided by the $\mu \mathrm{g} C$ lost via the sum of daytime and nighttime respiration $\mathrm{hr}^{-1}\left(R_{c}\right)$, assuming a mole-to-mole relationship of $\mathrm{O}_{2}$ consumed to $\mathrm{CO}_{2}$ produced during respiration (sensu Grottoli et al. 2006). Thus, $\mathrm{CHAR}_{\mathrm{DOC}}$ was calculated as:

$\mathrm{CHAR}_{\mathrm{DOC}}=\frac{D O C_{f}}{R_{c}} \times 100 \%$

Therefore, $\mathrm{CHAR}_{\mathrm{DOC}}$ is the percent of a coral's respiration that can be met or lost through DOC uptake or release. Negative $\mathrm{CHAR}_{\mathrm{DOC}}$ values indicate a net loss of DOC relative to respiratory demand, and positive CHAR $_{\text {DOC }}$ values indicate a net gain of DOC relative to respiratory demand.

\section{Statistical analyses}

To determine whether zooplankton capture differed by size and bleaching status, all zooplankton captured were converted into relative contributions by taxon and size class. These relative contributions were tested for differences across species and bleaching status using a factorial 
MANOVA. No differences in the composition of zooplankton taxa or size were found among species or bleaching status for either year (ESM Table S2). Therefore, data were pooled among experimental treatments and analyzed with one-way ANOVAs and Tukey tests to determine whether the proportion of captured zooplankton varied among size classes and taxa.

Data for coral feeding rates, DOC flux measurements, the $\mathrm{CHAR}_{\mathrm{DOC}}$, and CTAR estimates were non-normal, and variances were heterogeneous. Therefore, the effects of treatment (treatment, control) and time (0 and 11 months recovery during single bleaching and 0 months for repeat bleaching) on feeding rates, DOC fluxes, $\mathrm{CHAR}_{\mathrm{DOC}}$, and CTAR between treatment and control corals of each species at each time point were analyzed using the nonparametric Kruskal-Wallis test using SAS version 9.2. Values of $p \leq 0.05$ were considered significant.

Nonparametric two-way analysis of similarity (ANOSIM) was used to test for significant species ( $P$. divaricata, $P$. astreoides, $O$. faveolata) or bleaching event (single vs repeat) effects in total DOC and CTAR. Since total DOC encompasses both day and night DOC fluxes (see Fig. 4), the individual day and night DOC flux values were not used in the analysis. Since combining total DOC and CTAR did not change the results of the ANOSIM, we do not include those analyses here. Similarly, CTAR is comprised of several other measurements (see Fig. 5) that were not included in the ANOSIM for the same reason. ANOSIM analyses were done using Primer6.

\section{Results}

\section{Feeding}

Overall feeding rates did not differ between treatment and control corals of $P$. divaricata, $P$. astreoides, or $O$. faveolata after single or repeat bleaching (Fig. 2). However, $P$. astreoides feeding rates were higher than those of $P$. divaricata and $O$. faveolata (Fig. 2).

At the same time, the size and the relative abundances of zooplankton taxa captured by corals did not differ significantly by coral species or bleaching status in either year (ESM Table S2a). Therefore, all feeding data were pooled for each year to create an average assemblage composition of zooplankton captured by size and taxa (ESM Table S2b). Almost all $(95 \%)$ captured zooplankton were larger than $>400 \mu \mathrm{m}$ yet constituted $<20 \%$ of zooplankton availability on the reef (Fig. 3; ESM Fig S2). Between 28 and $69 \%$ of captured zooplankton were polychaetes, crab zoea, or unknown, even though these plankton represent $<1.5 \%$ of available zooplankton on the reef. Copepods represented one of the most frequently captured zooplankton types, yet their proportionate contribution to the zooplankton assemblage captured by corals is still lower than their availability on the reef. Approximately $82 \%$ of the zooplankton captured by singly bleached corals, in order of most to least captured, was unidentifiable zooplankton, crab zoea, polychaetes, and copepods (Fig. 3c). However, in repeat-bleached corals, $89 \%$ of the coral diet, in order of most to least captured, consisted of copepods, crab zoea, snails, and polychaetes (Fig. 3d).

\section{DOC fluxes}

Single and repeat bleaching had no significant effect on daytime or nighttime DOC fluxes of $P$. divaricata compared to controls (Fig. 4a, b). Overall, the net 24-h DOC fluxes were negative in both singly bleached and control corals due to the strong negative fluxes measured at night (Fig. 4c). Net 24-h DOC fluxes were positive for both treatment and control corals in the rest of the study due to consistently neutral or positive day and night fluxes (Fig. 4c).

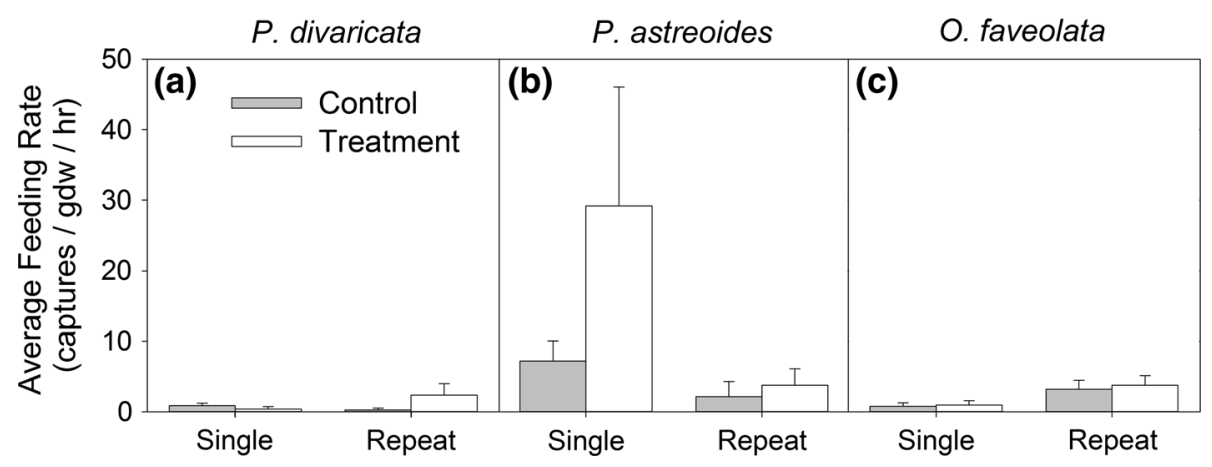

Fig. 2 Average feeding rate $( \pm S E)$ of coral fragments in control (gray bars) and bleached treatments (white bars) after single and repeat bleaching of a Porites divaricata, b Porites astreoides, and c Orbicella faveolata. Values are standardized to coral fragment grams dry weight per hour. Sample size for each average was 8 or 9 . No significant differences were detected between treatment and control average pairs using Kruskal-Wallis tests 

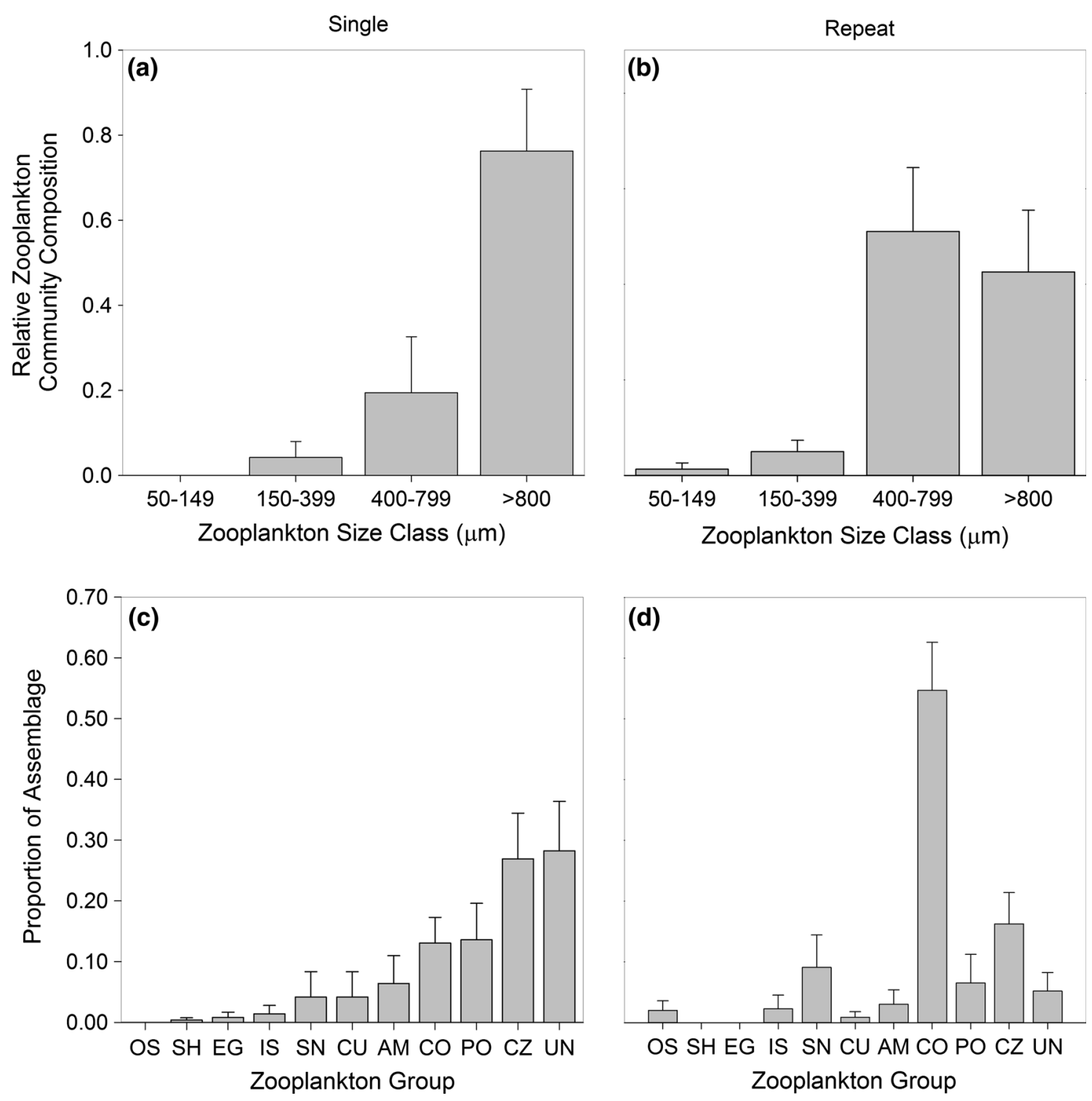

Fig. 3 Average proportion ( $\pm \mathrm{SE}$ ) of (a, b) size and (c, d) composition of zooplankton assemblage captured by corals exposed to ambient concentrations of zooplankton in $(\mathbf{a}, \mathbf{c})$ single- and (b, d) repeat-bleached corals. Zooplankton groups: $\mathrm{UN}=$ unidentified,

Singly bleached P. astreoides had lower daytime DOC fluxes than controls; this suppression of DOC flux persisted after 11 months on the reef (Fig. 4d). In contrast, repeat bleaching had no significant effect on daytime DOC fluxes. At night, DOC fluxes did not differ between treatment and control corals after single bleaching and 11 months on the reef, but repeat-bleached corals had greater DOC fluxes than controls (Fig. 4e). Integrated over $24 \mathrm{~h}$, treated $P$. astreoides took up DOC when singly bleached, but released DOC after 11 months on the reef and immediately after repeat bleaching (Fig. 4f). Net 24-h fluxes of the control corals were positive throughout the study (Fig. 4f).
$\mathrm{CZ}=$ crab zoea, $\mathrm{PO}=$ polychaetes, $\mathrm{CO}=$ copepods, $\mathrm{AM}=\mathrm{am}-$ phipods, $\mathrm{CU}=$ Cumacea, $\mathrm{SN}=$ snails, $\mathrm{IS}=$ isopods, $\mathrm{EG}=$ eggs, $\mathrm{SH}=$ shrimp, OS = ostracods

Like $P$. astreoides, singly bleached $O$. faveolata fragments had lower daytime DOC fluxes than controls (Fig. 4g). Nighttime DOC fluxes only differed between treatment and control corals after 11 months on the reef (Fig. 4h). Integrated over $24 \mathrm{~h}$, treated $O$. faveolata had negative DOC fluxes when singly bleached, but the controls had positive fluxes (Fig. 4i). As with $P$. divaricata and $P$. astreoides, net 24-h DOC fluxes did not differ between repeat-bleached and control $O$. faveolata corals and were positive (Fig. 4a-i).

Total DOC fluxes did not differ between species and only mildly differed between single and repeat bleaching 


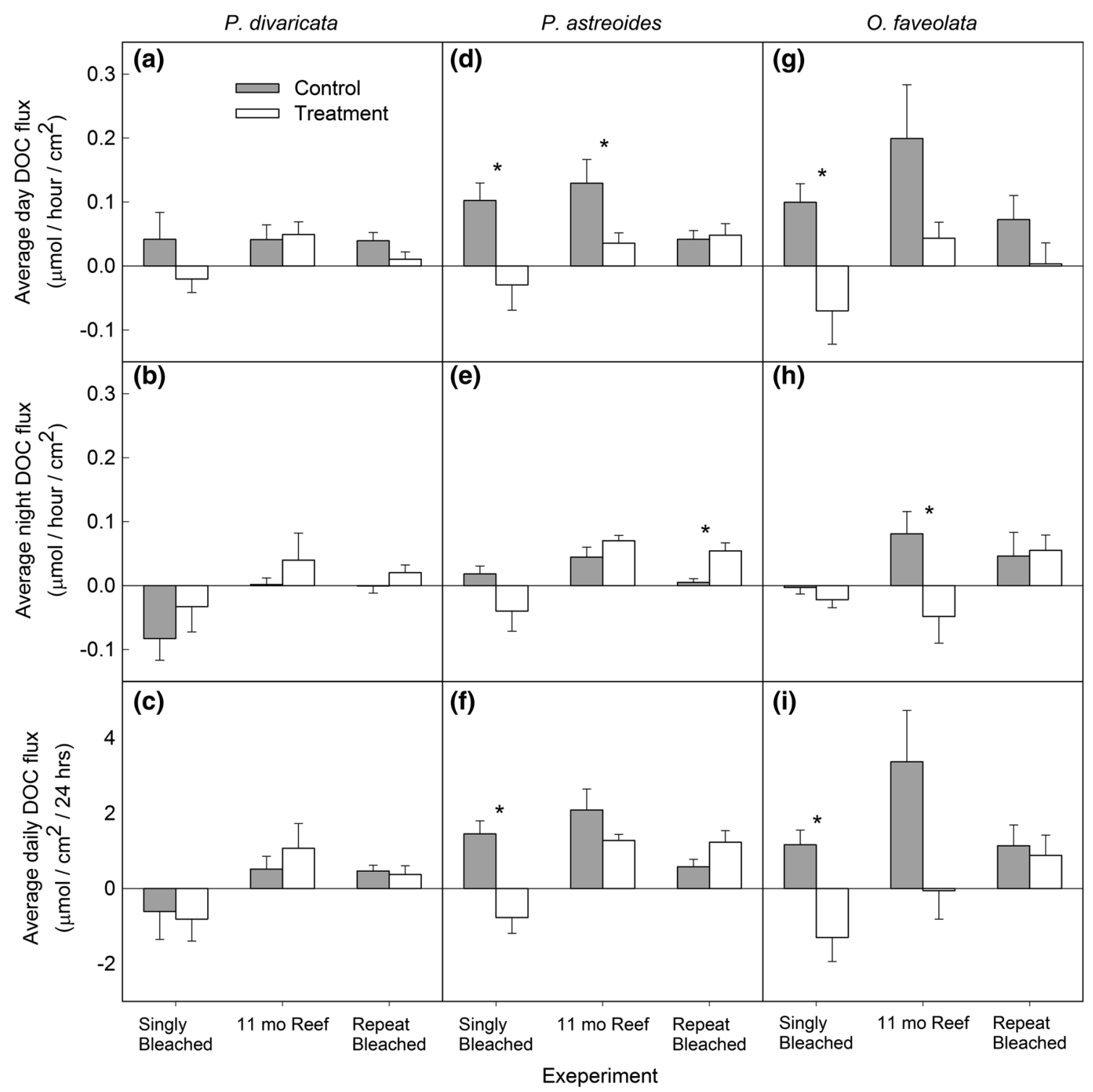

Fig. 4 Average DOC fluxes ( \pm SE) during a, d, g daytime, b, e, $\mathbf{h}$ nighttime, and $\mathbf{c}, \mathbf{f}, \mathbf{i}$ diurnal for control (gray bars) and treatment (white bars) Porites divaricata $(\mathbf{a}, \mathbf{b}, \mathbf{c})$, Porites astreoides $(\mathbf{d}, \mathbf{e}, \mathbf{f})$, and Orbicella faveolata $(\mathbf{g}, \mathbf{h}, \mathbf{i})$ after single bleaching, 11 months on the reef, and repeat bleaching. All averages are standardized to coral

events (two-way ANOSIM; species: $R=0.027, \quad p=$ 0.082; bleaching events: $R=0.062, p=0.01$ ).

\section{Percent contribution of DOC and zooplankton to coral respiration}

Singly bleached $P$. divaricata, $P$. astreoides, and $O$. faveolata met 35,10 , and $16 \%$ of their daily metabolic demand from DOC uptake, respectively, but control corals lost $1-10 \%$ of their total fixed carbon through DOC release (Fig. 5a-c). However, only singly bleached $O$. faveolata had significantly greater $\mathrm{CHAR}_{\mathrm{DOC}}$ than the controls surface area and time. Negative fluxes indicate uptake, while positive fluxes are release of DOC. For each species, asterisks indicate significant differences at $p \leq 0.05$ between treatment means within a time interval using Kruskal-Wallis tests. Sample sizes for each average ranged from 5 to 9

(Fig. 5c). As previously shown in Grottoli et al. (2014), zooplankton contributed $<15 \%$ of total metabolic demand in $P$. divaricata and $O$. faveolata irrespective of bleaching at any time (Fig. 5d, f). However, zooplankton feeding contributed dramatically to metabolic demand in the controls $(50 \%)$ and treatment corals $(140 \%)$ following single bleaching of $P$. astreoides (Fig. 5e). While the contribution of zooplankton feeding to CTAR has already been documented (Grottoli et al. 2014) (Fig. 5g-i), the addition of CHAR $_{\text {DOC }}$ to CTAR from Grottoli et al. (2014) resulted in a net increase in total CTAR in singly bleached corals and a slight decrease in their respective controls (Fig. 5g-i). 

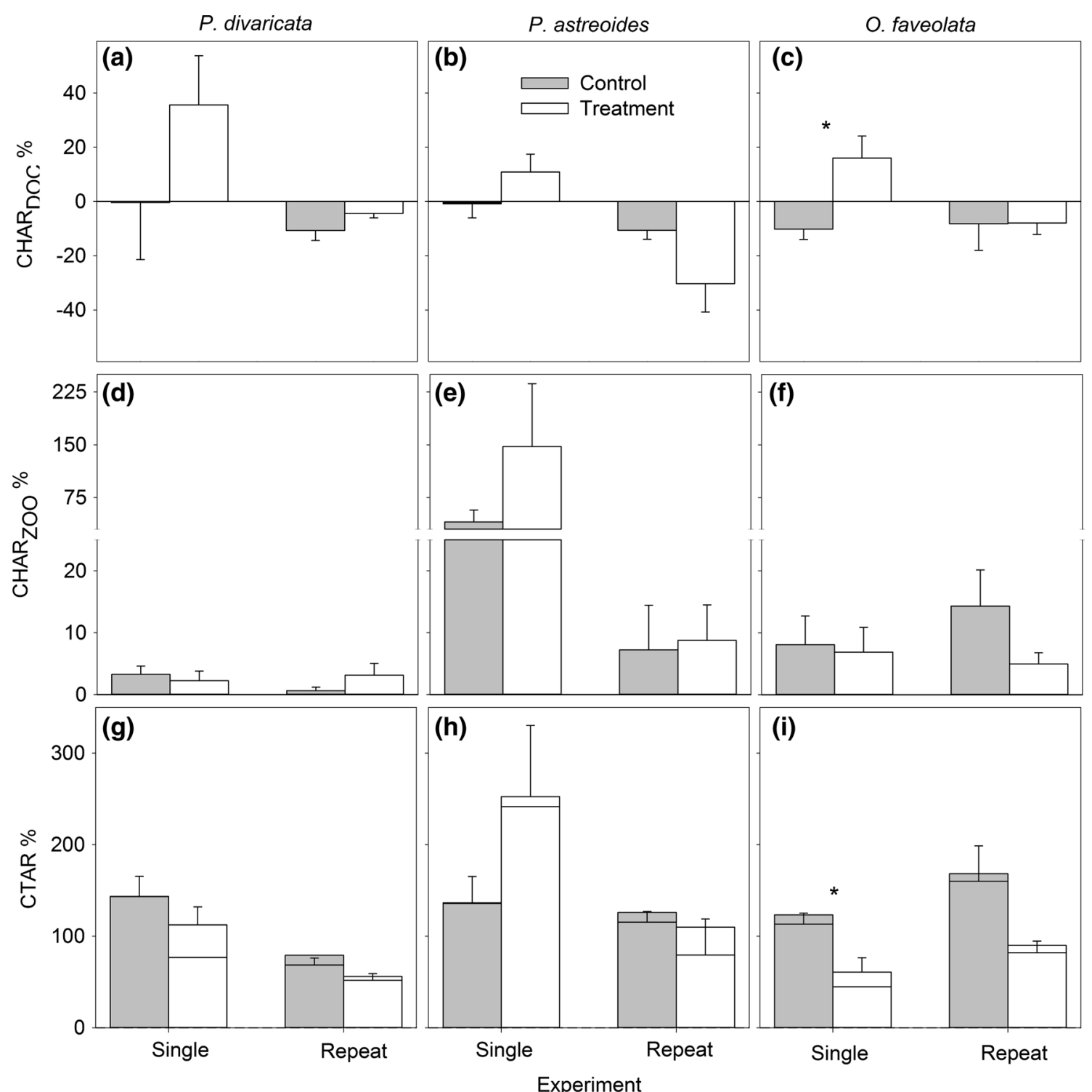

Fig. 5 Average $( \pm \mathrm{SE}) \mathbf{a}, \mathbf{b}, \mathbf{c} \mathrm{CHAR}_{\mathrm{DOC}}, \mathbf{d}, \mathbf{e}, \mathbf{f} \mathrm{CHAR}_{\mathrm{ZOO}}$, and $\mathbf{g}, \mathbf{h}$, i CTAR in control (gray bars) and treatment (white bars) for Porites divaricata $(\mathbf{a}, \mathbf{d}, \mathbf{g})$, Porites astreoides $(\mathbf{b}, \mathbf{e}, \mathbf{h})$, and Orbicella faveolata $(\mathbf{c}, \mathbf{f}, \mathbf{i})$ after single and repeat bleaching. $\mathrm{CHAR}_{\mathrm{ZOO}}$ values from Grottoli et al. (2014). For CTAR graphs $(\mathbf{g}, \mathbf{h}, \mathbf{i})$, lines without error bars represent CTAR values from Grottoli et al. (2014) without $\mathrm{CHAR}_{\mathrm{DOC}}$ values. For each species, asterisks indicate significant differences at $p \leq 0.05$ between treatment means within a time interval using Kruskal-Wallis tests

$(\mathrm{R}=0.066, p=0.014)$ or $O$. faveolata $(R=0.071$, $p=0.015)$.

\section{Discussion}

Previous studies have established that some thermally stressed corals are capable of utilizing zooplankton heterotrophy and DOC to meet metabolic demand and recover more quickly Grottoli et al. (2006, 2014). However, this is the first study to quantify the relative contribution of each pathway to the $\mathrm{C}$ budget of bleached corals 
and assess whether this heterotrophic plasticity was affected by increased frequency of bleaching events.

\section{Coral feeding}

Similar to Montipora capitata in Hawaii (Grottoli et al. 2006; Palardy et al. 2008), P. astreoides could completely meet its metabolic demand from zooplankton heterotrophy when initially bleached (Grottoli et al. 2014). However, neither singly bleached $P$. divaricata nor $O$. faveolata exhibited any heterotrophic plasticity (Fig. 2a, c), and they could not meet their metabolic demand after single bleaching (Grottoli et al. 2014). Interestingly, none of the species studied here were able to increase their feeding rates (Fig. 2), nor meet their metabolic demand following repeat bleaching (Grottoli et al. 2014). This suggests that for $P$. astreoides, the cumulative impact of multiple bleaching events inhibits zooplankton heterotrophy and corroborates previous findings by Grottoli et al. (2014) that acclimatization and/or resilience to multiple bleaching events is independent of zooplankton heterotrophy for all three species.

Uniformity in zooplankton size and community composition captured among coral species within each year, irrespective of bleaching status, is consistent with findings from previous studies where the size and taxa of zooplankton captured were the same regardless of coral species, polyp size, morphology, and depth (Sebens et al. 1996; Palardy et al. 2005, 2006, 2008). As with other Caribbean corals (Sebens et al. 1996), the vast majority of zooplankton captured in this study were relatively large $(>400 \mu \mathrm{m})$ and consisted of crab zoea, polychaetes, and copepods or were unidentified. Our data show that all three species of coral were selectively feeding on copepods, crab zoea, and polychaetes $>400 \mu \mathrm{m}$ independently of their abundance on the reef (Fig. 3; ESM Fig. S2). This contrasts with Pacific corals where $\sim 70 \%$ of the zooplankton captured were much smaller $(<400 \mu \mathrm{m})$ and primarily amphipods, crab zoea, isopods, and larval shrimp (Palardy et al. 2006, 2008). Thus, the size and preferred taxa of zooplankton captured by corals appear to differ between Pacific and Caribbean species.

Some studies suggest that climate change will reduce zooplankton population abundances (Tada et al. 2003; Piontkovski and Castellani 2009). This may ultimately decrease the potential resilience of corals that increase their heterotrophic subsidies in response to a single bleaching event such as $P$. astreoides (this study) and $M$. capitata (Grottoli et al. 2006; Palardy et al. 2008). However, since none of the Caribbean species studied here displayed any heterotrophic plasticity following repeat bleaching (Fig. 2) and zooplankton represented $<9 \%$ of daily metabolic demand when corals were repeat-bleached (Grottoli et al.
2014) (Fig. 5d-f), any long-term changes in reef zooplankton abundance may have little to no effect on coral resilience to repeated bleaching stress.

\section{Daily DOC fluxes}

Throughout the study, non-bleached control $P$. astreoides and $O$. faveolata released DOC (Fig. 4f, i), consistent with findings from most previous studies of healthy nonbleached coral DOC fluxes (Crossland 1987; Wild et al. 2004, 2005, 2008, 2010a, b; Tanaka et al. 2008, 2009; Haas et al. 2010; Naumann et al. 2010; Levas et al. 2015). At the same time, non-bleached control $P$. divaricata took up DOC after the single bleaching event (Fig. 4c), just as did healthy Pocillopora sp., Fungia sp., and Stylophora pistillata (Naumann et al. 2010; Tremblay et al. 2012). However, similar to $P$. astreoides and $O$. faveolata, nonbleached control $P$. divaricata released DOC during the remainder of the study (Fig. 4c). These findings further show that while DOC typically represents a loss of $\mathrm{C}$ from healthy corals, it can sometimes also be a source of C.

When singly bleached, all three species in this study took up DOC (Fig. 4c, f, i). While this is consistent with DOC uptake observed for bleached P. lobata (Levas et al. 2013), it contrasts with other findings of DOC release for bleached Acropora sp., Porites spp., and S. pistillata (Niggl et al. 2009; Haas et al. 2010). Naumann et al. (2010) inferred that DOC uptake in non-bleached corals was the result of heterotrophic microbial activity at the coral surface and not due to active uptake by the coral host. Conversely, Haas et al. (2010) hypothesized that DOC uptake in one species of stressed Manicinia was the result of active DOC ingestion by the coral in direct response to temperature stress. The plasticity of DOC flux observed in all three species in this study suggests that some species of bleached corals do take up DOC as a source of fixed C. The ability of singly bleached $P$. divaricata, $P$. astreoides, and $O$. faveolata to utilize DOC as a fixed C source could provide these corals with a significant advantage over species that are incapable of doing so when bleached.

After 11 months on the reef, singly bleached $P$. astreoides had recovered its DOC fluxes and released DOC (Fig. 4f). Porites divaricata DOC fluxes never differed from controls, indicating that DOC fluxes were not sensitive to bleaching in this species. However, both bleached and non-bleached $P$. divaricata displayed a seasonal pattern in their DOC fluxes that had not been previously observed-both had negative DOC flux in late summer (after single bleaching) and positive flux 11 months later in late spring/early summer (Fig. 4c). Only one species of healthy coral has shown significant seasonal differences in the magnitude of DOC release (Naumann et al. 2010), but with no change in the direction of DOC flux. These 
findings suggest that DOC fluxes in these Caribbean corals are not only highly species specific and affected by seasonality, but also driven by the bleaching status of the coral.

Although all singly bleached corals took up DOC, all repeat-bleached corals released DOC to the same extent as the control corals (Fig. 4c, f, i). This suggests that repeat bleaching altered the capacity of corals to utilize DOC as a fixed C source. Thus, it appears that repeat-bleached corals are unable to obtain supplemental heterotrophic nutrition from either DOC (Fig. 4) or zooplankton feeding (Fig. 2), making them even more dependent on either energy reserves (Anthony et al. 2009; Grottoli et al. 2014) or shifts in Symbiodinium type (Thornhill et al. 2006; LaJeunesse et al. 2009; Grottoli et al. 2014) to survive annual bleaching events.

\section{Contribution of DOC to animal respiration (CHAR $_{\text {DOC }}$ )}

\section{Single bleaching}

When singly bleached, $P$. divaricata, $P$. astreoides, and $O$. faveolata were able to supplement their $\mathrm{C}$ budget by taking up DOC as a source of heterotrophic C (Fig. 5a-c). With the large addition of $\mathrm{CHAR}_{\mathrm{DOC}}$, the overall CTAR budget for singly bleached $P$. divaricata was $>100 \%$ and no longer significantly different from non-bleached controls corals as was the case without CHAR $_{\text {DOC }}$ in Grottoli et al. (2014) (Fig. 5g). Other studies have shown that some species of corals are capable of taking up DOC when bleached or thermally stressed (Haas et al. 2010; Levas et al. 2013). Thus, DOC uptake can serve as a critical mechanism for some species to maintain their $\mathrm{C}$ budgets when singly bleached and to promote recovery from bleaching.

In contrast, the significant increase in zooplankton feeding (Fig. 2b) in singly bleached $P$. astreoides accounted for more than $140 \%$ of its total C budget (Grottoli et al. 2014) (Fig. 5d), and the additional $10 \%$ from CHAR $_{\text {DOC }}$ served to further magnify its $\mathrm{C}$ budget surplus (Fig. $5 \mathrm{~g}$ ). This large CTAR surplus most likely played a role in the rapid recovery of this coral from single bleaching (Grottoli et al. 2014). Similar dramatic increases in zooplankton feeding have also been observed in singly bleached Hawaiian $M$. capitata and resulted in CTAR < $100 \%$ (Grottoli et al. 2006; Palardy et al. 2008) accompanied by rapid recovery of energy reserves, and maintenance of normal spawning rates the year following bleaching (Cox 2007). Therefore, increased zooplankton feeding is a strong mechanism for some species to maintain their $\mathrm{C}$ budgets when singly bleached and to promote recovery from bleaching.

Finally, singly bleached $O$. faveolata had low feeding rates (Fig. 3c) and were not able to make up for the $\mathrm{C}$ budget deficit through feeding on zooplankton (Fig. 5f) nor by taking up DOC as a fixed $\mathrm{C}$ source (Fig. 5c, i). Even were this species to gain a potential $8 \%$ more CHAR from eating pico- and nano-plankton (Tremblay et al. 2012) or other sources such as sediment organic matter and particulate organic matter that were not measured here and may play a vital role in coral heterotrophy, it would not be sufficient additional heterotrophic $\mathrm{C}$ to bring its CTAR up to $100 \%$ and meet daily metabolic demand. Of the three species, $O$. faveolata was also the only species that did not recover calcification rates and had increased levels of the Symbiodinium trenchii (ITS-type D1a) within 6 weeks following single bleaching (Grottoli et al. 2014). Thus, heterotrophy by $O$. faveolata cannot compensate for reduced CTAR due to dramatic decreases in photosynthesis during single bleaching (Grottoli et al. 2014). As such, prolonged periods of a deficient $\mathrm{C}$ budget could put this species at particular risk during long bleaching events.

Irrespective of the total $\mathrm{C}$ obtained by singly bleached corals, DOC represents a significant source of fixed carbon to these corals (Fig. $5 \mathrm{a}-\mathrm{c}$ ). $\mathrm{CHAR}_{\mathrm{DOC}}$ values ranged from 11 to $36 \%$ and represented a greater source of heterotrophic carbon to singly bleached $P$. divaricata and $O$. faveolata than did zooplankton feeding (Fig. 5d-f). Alterations to the quantity, composition, and quality of coral reef DOC pools by climate change, as predicted by Brocke et al. (2015), could impact those corals that rely on DOC as a C source when singly bleached.

\section{Repeat bleaching}

Interestingly, all three species of corals lost DOC when repeat-bleached; $\mathrm{CHAR}_{\mathrm{DOC}}$ losses were greatest in $P$. astreoides and least in $P$. divaricata (Fig. 4c, f, i). These DOC loses exacerbated the $\mathrm{C}$ limitation already caused by significant declines in photosynthesis (Grottoli et al. 2014) and resulted in a decline in the CTAR of all three species. None of the repeat-bleached corals were able to meet metabolic demand (CTAR < $100 \%$ ) (Fig. 5g-i). Declines in CTAR values most likely contributed to the dramatic declines in energy reserves and calcification in both repeatbleached $P$. astreoides and $O$. faveolata (Grottoli et al. 2014). Even though $P$. divaricata had the lowest CTAR values of all three species, the values did not differ between repeat-bleached and control fragments (Fig. 5g). In addition, this species had lower chlorophyll $a$ levels after repeat bleaching (Schoepf et al. 2014) but was otherwise unaffected and maintained its endosymbiont density, high levels of energy reserves, and calcification rates (Grottoli et al. 2014), suggesting that $P$. divaricata obtained additional fixed $\mathrm{C}$ from a source that was not quantified in this study (possibly particulate organic carbon $<50 \mu \mathrm{m}$ ). Coupled with the shuffling of its Symbiodinium (Grottoli et al. 
2014) and the smallest CHAR $_{\text {DOC }}$ losses of all three species, $P$. divaricata appears to have several physiological traits that facilitate acclimatization to repeated bleaching stress. However, prolonged periods of a $\mathrm{C}$ deficiency could put species like $P$. astreoides and $O$. faveolata at particular risk of death in the future if bleaching events occur annually and are longer in duration. Overall, these findings add to the growing body of evidence that annual bleaching may lead to a decline in both $P$. astreoides and $O$. faveolata abundance, but that corals like $P$. divaricata could rapidly acclimatize and persist. While previous studies have suggested that some corals can acclimatize to bleaching events separated by several years (Maynard et al. 2008; Middlebrook et al. 2008; Bellantuono et al. 2012; Guest et al. 2012; McClanahan and Muthiga 2014), they have not shed light on coral responses to annual bleaching. This study is the first to show that at least one Caribbean coral could rapidly acclimate to annual bleaching, but that other species may be at risk of significant decline in the face of annual bleaching stress.

\section{Implications}

Our findings showed that DOC and zooplankton can represent significant sources of organic $\mathrm{C}$ for some bleached and healthy Caribbean corals. However, the proportionate contribution of DOC and zooplankton varied with bleaching status, bleaching frequency, seasons, and among species. While DOC was a critical source of organic $\mathrm{C}$ for singly bleached $P$. divaricata and zooplankton for singly bleached $P$. astreoides, neither contributed meaningfully to the $\mathrm{C}$ budget of repeat-bleached corals in any of the three species. In fact, DOC losses resulted in an increased $\mathrm{C}$ deficiency for repeat-bleached corals rather than mitigating resource limitation. This suggests that the capacity for heterotrophic plasticity (i.e., DOC uptake and zooplankton feeding) in corals is compromised under annual bleaching stress and that any climate change-driven changes in the quality or quantity of reef seawater DOC or zooplankton (Tada et al. 2003; Piontkovski and Castellani 2009; Brocke et al. 2015) are therefore not likely to have an impact on coral resilience to annual bleaching. This is in direct contrast to single isolated bleaching events where both DOC and zooplankton feeding can be vital to maintaining coral C budgets and promoting recovery (Grottoli et al. 2006, 2014; Palardy et al. 2008; Levas et al. 2013). Instead, other physiological variables such as energy reserves (Rodrigues and Grottoli 2007; Anthony et al. 2009; Grottoli et al. 2014) and Symbiodinium shuffling (Thornhill et al. 2006; LaJeunesse et al. 2009; Grottoli et al. 2014) are more likely to dictate which species or populations of species are expected to survive and persist in a future with annual bleaching.
Acknowledgments We thank Roberto Iglesias-Prieto, Ania Banaszak, Susana Enriquez, Robin Smith, and the staff of the Instituto de Ciencias del Mar y Limnologia, Universidad Nacional Autonoma de Mexico for their generous time and logistical support. We also thank Yohei Matsui, Teresa Huey, Dana Borg, and Amy Barrett for field and laboratory assistance. This research was funded by the National Science Foundation division of Biological Oceanography grants OCE-0825490 to AG and OCE-0825413 to MW. We also thank the Ford Foundation. Data archived at http://www.bco-dmo.org/project/516103. All work undertaken in this study complied with the current laws of Mexico and the USA.

\section{References}

Anthony KRN (1999) Coral suspension feeding on fine particulate matter. J Exp Mar Bio Ecol 232:85-106

Anthony KRN (2000) Enhanced particle-feeding capacity of corals on turbid reefs (Great Barrier Reef, Australia). Coral Reefs 19:59-67

Anthony KRN, Hoogenboom MO, Maynard JA, Grottoli AG, Middlebrook R (2009) Energetics approach to predicting mortality risk from environmental stress: a case study of coral bleaching. Funct Ecol 23:539-550

Bellantuono AJ, Hoegh-Guldberg O, Rodriguez-Lanetty M (2012) Resistance to thermal stress in corals without changes in symbiont composition. Proc Roy Soc Lond B Biol Sci 279:1100-1107

Brocke HJ, Wenzhoefer F, de Beer D, Mueller B, van Duyl FC, Nugues MM (2015) High dissolved organic carbon release by benthic cyanobacterial mats in a Caribbean reef ecosystem. Sci Rep 5:8852

Brown BE (1997) Coral bleaching: causes and consequences. Coral Reefs 16:S129-S138

Bythell JC (1988) A total nitrogen and carbon budget for the elkhorn coral Acropora palmata (Lamarck). Proc 6th Int Coral Reef Symp 2:535-540

Cox EF (2007) Continuation of sexual reproduction in Montipora capitata following bleaching. Coral Reefs 26:721-724

Crossland CJ (1987) In situ release of mucus and DOC-lipid from the corals Acropora variabilis and Stylophora pistillata in different light regimes. Coral Reefs 6:35-42

Crossland CJ, Barnes DJ, Borowitzka MA (1980) Diurnal lipid and mucus production in the staghorn coral Acropora acuminata. Mar Biol 60:81-90

D’Croz L, Mate JL, Oke JE (2001) Responses to elevated seawater temperature and UV radiation in the coral Porites lobata from upwelling and non-upwelling environments on the Pacific coast of Panama. Bull Mar Sci 69:203-214

Donner SD, Knutson TR, Oppenheimer M (2007) Model-based assessment of the role of human-induced climate change in the 2005 Caribbean coral bleaching event. Proc Natl Acad Sci USA 104:5483-5488

Edmunds PJ, Davies PS (1986) An energy budget for Porites porites (Scleractinia). Mar Biol 92:339-347

Falkowski PG, Dubinsky Z, Muscatine L, Mccloskey L (1993) Population control in symbiotic corals. Bioscience 43:606-611

Ferrier-Pages C, Gattuso JP, Cauwet G, Jaubert J, Allemand D (1998) Release of dissolved organic carbon and nitrogen by the zooxanthellate coral Galaxea fascicularis. Mar Ecol Prog Ser 172:265-274

Ferrier-Pages C, Peirano A, Abbate M, Cocito S, Negri A, Rottier C, Riera P, Rodolfo-Metalpa R, Reynaud S (2011) Summer autotrophy and winter heterotrophy in the temperate symbiotic coral Cladocora caespitosa. Limnol Oceanogr 56:1429-1438 
Frieler K, Meinshausen M, Golly A, Mengel M, Lebek K, Donner SD, Hoegh-Guldberg O (2013) Limiting global warming to $2 \mathrm{C}$ is unlikely to save most coral reefs. Nat Clim Chang 3:165-170

Glynn PW (1996) Coral reef bleaching: facts, hypotheses and implications. Glob Chang Biol 2:495-509

Grottoli AG, Rodrigues LJ, Palardy JE (2006) Heterotrophic plasticity and resilience in bleached corals. Nature 440:1186-1189

Grottoli AG, Warner ME, Levas SJ, Aschaffenburg MD, Schoepf V, McGinley M, Baumann J, Matsui Y (2014) The cumulative impact of annual coral bleaching can turn some coral species winners into losers. Glob Chang Biol 20:3823-3833

Guest JR, Baird AH, Maynard JA, Muttaqin E, Edwards AJ, Campbell SJ, Yewdall K, Affendi YA, Chou LM (2012) Contrasting patterns of coral bleaching susceptibility in 2010 suggest an adaptive response to thermal stress. PLoS One 7:e33353

Haas AF, Jantzen C, Naumann MS, Iglesias-Prieto R, Wild C (2010) Organic matter release by the dominant primary producers in a Caribbean reef lagoon: implication for in situ $\mathrm{O}_{2}$ availability. Mar Ecol Prog Ser 409:27-39

Hoegh-Guldberg O (1999) Climate change, coral bleaching and the future of the world's coral reefs. Mar Freshw Res 50:839-866

Houlbreque F, Ferrier-Pages C (2009) Heterotrophy in tropical scleractinian corals. Biol Rev Camb Philos Soc 84:1-17

Jokiel PL, Coles SL (1990) Response of Hawaiian and other IndoPacific reef corals to elevated temperature. Coral Reefs 8:155-162

LaJeunesse TC, Smith RT, Finney J, Oxenford H (2009) Outbreak and persistence of opportunistic symbiotic dinoflagellates during the 2005 Caribbean mass coral 'bleaching' event. Proc R Soc Lond B Biol Sci 276:4139-4148

Leal MC, Ferrier-Pages C, Calado R, Brandes JA, Frischer ME, Nejstgaard JC (2014) Trophic ecology of the facultative symbiotic coral Oculina arbuscula. Mar Ecol Prog Ser 504:171-179

Levas SJ, Grottoli AG, Hughes A, Osburn CL, Matsui Y (2013) Physiological and biogeochemical traits of bleaching and recovery in the mounding species of coral Porites lobata: implications for resilience in mounding corals. PLoS One 8:e63267

Levas S, Grottoli AG, Warner ME, Cai WJ, Bauer J, Schoepf V, Baumann JH, Matsui Y, Gearing C, Melman TF, Hoadley KD, Pettay DT, Hu X, Li Q, Xu H, Wang Y (2015) Organic carbon fluxes mediated by corals at elevated $\mathrm{pCO}_{2}$ and temperature. Mar Ecol Prog Ser 519:153-164

Marsh JA (1970) Primary productivity of reef-building calcareous red algae. Ecology 51:255-263

Maynard JA, Anthony KRN, Marshall PA, Masiri I (2008) Major bleaching events can lead to increased thermal tolerance in corals. Mar Biol 155:173-182

McClanahan TR, Muthiga NA (2014) Community change and evidence for variable warm-water temperature adaptation of corals in northern Male Atoll, Maldives. Mar Pollut Bull 80:107-113

Middlebrook R, Hoegh-Guldberg O, Leggat W (2008) The effect of thermal history on the susceptibility of reef-building corals to thermal stress. J Exp Biol 211:1050-1056

Muscatine L, Mccloskey LR, Marian RE (1981) Estimating the daily contribution of carbon from zooxanthellae to coral animal respiration. Limnol Oceanogr 26:601-611

Naumann MS, Haas A, Struck U, Mayr C, El-Zibdah M, Wild C (2010) Organic matter release by dominant hermatypic corals of the northern Red Sea. Coral Reefs 29:649-659

Naumann MS, Richter C, Mott C, el-Zibdah M, Manasrah R, Wild C (2012) Budget of coral-derived organic carbon in a fringing coral reef of the Gulf of Aqaba, Red Sea. J Mar Syst 105:20-29
Niggl W, Glas M, Laforsch C, Mayr C, Wild C (2009) First evidence of coral bleaching stimulating organic matter release by reef corals. Proc 11th Int Coral Reef Symp, pp 905-911

Palardy JE, Grottoli AG, Matthews KA (2005) Effects of upwelling, depth, morphology and polyp size on feeding in three species of Panamanian corals. Mar Ecol Prog Ser 300:79-89

Palardy JE, Grottoli AG, Matthews KA (2006) Effect of naturally changing zooplankton concentrations on feeding rates of two coral species in the eastern Pacific. J Exp Mar Bio Ecol 331:99-107

Palardy JE, Rodrigues LJ, Grottoli AG (2008) The importance of zooplankton to the daily metabolic carbon requirements of healthy and bleached corals at two depths. J Exp Mar Bio Ecol 367:180-188

Piontkovski SA, Castellani C (2009) Long-term declining trend of zooplankton biomass in the tropical Atlantic. Hydrobiologia 632:365-370

Rodrigues LJ, Grottoli AG (2007) Energy reserves and metabolism as indicators of coral recovery from bleaching. Limnol Oceanogr 52:1874-1882

Schoepf V, McCulloch MT, Warner ME, Levas SJ, Matsui Y, Aschaffenburg MD, Grottoli AG (2014) Short-term coral bleaching is not recorded by skeletal boron isotopes. PLoS One 9:e112011

Sebens KP, Vandersall KS, Savina LA, Graham KR (1996) Zooplankton capture by two scleractinian corals, Madracis mirabilis and Montastrea cavernosa, in a field enclosure. Mar Biol 127:303-317

Tada K, Sakai K, Nakano Y, Takemura A, Montani S (2003) Sizefractionated phytoplankton biomass in coral reef waters off Sesoko Island, Okinawa, Japan. J Plankton Res 25:991-997

Tanaka Y, Miyajima T, Koike I, Hayashibara T, Ogawa H (2008) Production of dissolved and particulate organic matter by the reef-building corals Porites cylindrica and Acropora pulchra. Bull Mar Sci 82:237-245

Tanaka Y, Miyajima T, Umezawa Y, Hayashibara T, Ogawa H, Koike I (2009) Net release of dissolved organic matter by the scleractinian coral Acropora pulchra. J Exp Mar Bio Ecol 377:101-106

Thornhill DJ, LaJeunesse TC, Kemp DW, Fitt WK, Schmidt GW (2006) Multi-year, seasonal genotypic surveys of coral-algal symbioses reveal prevalent stability or post-bleaching reversion. Mar Biol 148:711-722

Tremblay P, Naumann MS, Sikorski S, Grover R, Ferrier-Pages C (2012) Experimental assessment of organic carbon fluxes in the scleractinian coral Stylophora pistillata during a thermal and photo stress event. Mar Ecol Prog Ser 453:63-77

van Hooidonk R, Maynard JA, Liu Y, Lee SK (2015) Downscaled projections of Caribbean coral bleaching that can inform conservation planning. Glob Chang Biol 21:3389-3401

Wild C, Woyt H, Huettel M (2005) Influence of coral mucus on nutrient fluxes in carbonate sands. Mar Ecol Prog Ser 287:87-98

Wild C, Naumann M, Niggl W, Haas A (2010a) Carbohydrate composition of mucus released by scleractinian warm- and coldwater reef corals. Aquat Biol 10:41-45

Wild C, Niggl W, Naumann MS, Haas AF (2010b) Organic matter release by Red Sea coral reef organisms-potential effects on microbial activity and in situ $\mathrm{O}_{2}$ availability. Mar Ecol Prog Ser 411:61-71

Wild C, Huettel M, Klueter A, Kremb SG, Rasheed MY, Jorgensen BB (2004) Coral mucus functions as an energy carrier and particle trap in the reef ecosystem. Nature 428:66-70

Wild C, Mayr C, Wehrmann L, Schottner S, Naumann M, Hoffmann F, Rapp HT (2008) Organic matter release by cold water corals and its implication for fauna-microbe interaction. Mar Ecol Prog Ser 372:67-75

Wilkinson C (2008) Status of coral reefs of the world 2008. Global Coral Reef Monitoring Network and Reef and Rainforest Research Centre, Townsville 